\title{
Genome editing with CRISPR/Cas9 in Pinus radiata (D. Don)
}

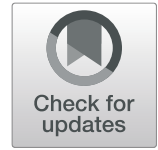

\author{
Charleson Poovaiah * ${ }^{*}$, Lorelle Phillips, Barbara Geddes, Cathie Reeves, Mathias Sorieul and Glenn Thorlby
}

\begin{abstract}
Background: To meet increasing demand for forest-based products and protect natural forests from further deforestation requires increased productivity from planted forests. Genetic improvement of conifers by traditional breeding is time consuming due to the long juvenile phase and genome complexity. Genetic modification (GM) offers the opportunity to make transformational changes in shorter time frames but is challenged by current genetically modified organism (GMO) regulations. Genome editing, which can be used to generate site-specific mutations, offers the opportunity to rapidly implement targeted improvements and is globally regulated in a less restrictive way than GM technologies.

Results: We have demonstrated CRISPR/Cas9 genome editing in P. radiata targeting a single-copy cell wall gene GUX1 in somatic embryogenic tissue and produced plantlets from the edited tissue. We generated biallelic INDELs with an efficiency of $15 \%$ using a single gRNA. $12 \%$ of the transgenic embryogenic tissue was edited when two gRNAs were used and deletions of up to $1.3 \mathrm{~kb}$ were identified. However, the regenerated plants did not contain large deletions but had single nucleotide insertions at one of the target sites. We assessed the use of CRISPR/Cas9 ribonucleoproteins (RNPs) for their ability to accomplish DNA-free genome editing in P. radiata. We chose a hybrid approach, with RNPs codelivered with a plasmid-based selectable marker. A two-gRNA strategy was used which produced an editing efficiency of $33 \%$, and generated INDELs, including large deletions. Using the RNP approach, deletions found in embryogenic tissue were also present in the plantlets. But, all plants produced using the RNP strategy were monoallelic.

Conclusions: We have demonstrated the generation of biallelic and monoallelic INDELs in the coniferous tree P. radiata with the CRISPR/Cas9 system using plasmid expressed Cas9 gRNA and RNPs respectively. This opens the opportunity to apply genome editing in conifers to rapidly modify key traits of interest.
\end{abstract}

Keywords: Genome editing, CRISPR, Somatic embryogenesis, Pinus radiata, Conifers

\section{Background}

Population growth, coupled with the need to transition from a petrochemical-based economy towards a more sustainable bio-based one, is predicted to increase the demand for wood and other forest-based products three-fold by 2050 [1]. This increased demand, together with the challenges associated with climate change and the need to increase agricultural production, will put further pressure on the area and quality of natural

\footnotetext{
* Correspondence: Charleson.Poovaiah@scionresearch.com
} Scion, Rotorua 3010, New Zealand forests. It has been estimated that planted forests, which comprise only $7 \%$ of the global forest area, have the potential to supply two-thirds of global roundwood demand [2] and offer a route to sustainably increase the production of forest products and reduce pressure on natural forests. To meet the increased demand, it will be necessary to further increase the productivity of planted forests.

There is a long history of productivity improvements in commercially planted conifer species through traditional breeding and silviculture [3, 4]. The use of genomic-based breeding technologies, particularly the

(c) The Author(s). 2021 Open Access This article is licensed under a Creative Commons Attribution 4.0 International License, which permits use, sharing, adaptation, distribution and reproduction in any medium or format, as long as you give appropriate credit to the original author(s) and the source, provide a link to the Creative Commons licence, and indicate if changes were made. The images or other third party material in this article are included in the article's Creative Commons licence, unless indicated otherwise in a credit line to the material. If material is not included in the article's Creative Commons licence and your intended use is not permitted by statutory regulation or exceeds the permitted use, you will need to obtain permission directly from the copyright holder. To view a copy of this licence, visit http://creativecommons.org/licenses/by/4.0/ The Creative Commons Public Domain Dedication waiver (http://creativecommons.org/publicdomain/zero/1.0/) applies to the data made available in this article, unless otherwise stated in a credit line to the data. 
implementation of genomic selection, are also showing promise for implementation into breeding programs [57]. Long breeding cycles, large and complex genomes, variable juvenile-mature correlations, emerging pests and diseases, climate, and market changes provide challenges to breeding approaches that have to date led to moderate gains in conifers $[6,8]$.

Direct manipulation of conifer genomes offers a potentially more rapid route to trait improvement and allows the introduction of novel traits as well as improvement of existing ones. Demonstrated trait modifications in conifers include; insect resistance $[9,10]$, herbicide tolerance $[11,12]$, wood pulping efficiency $[13$, 14], stress tolerance [15] and sterility [16]. These technologies also enable production of rationally designed trees that produce biochemicals and biomass for specific purposes [17], yet, no modified conifers have been commercialized. These modification technologies require the introduction of new genes either via Agrobacterium or biolistic based methods [18]. But, the transformation of conifers is challenging, relying on complex somatic embryogenesis protocols, with many species or genotypes proving recalcitrant to somatic embryogenesis protocols and/or transformation [18]. The lack of efficient transformation systems for elite germplasm intended for large-scale production remains a major challenge for genetically modified varietal forestry [19].

Over the last decade, genome editing, particularly the CRISPR/Cas9 system, has been widely used in plants, both for fundamental research and precision breeding [20-22], with the first genome-edited food introduced into the market in 2019 [23]. Novel traits or traits difficult to achieve by breeding, such as biotic- and abioticstress resistance [24-26], and sterility [27] can be generated by knockout-mediated trait improvement. Desirable traits can be fine-tuned by generating a range of alleles through either genome editing or base editing [28-31]. Successful demonstrations of editing have included trees like poplar and eucalyptus [32-35]. As far as we are aware, genome editing is yet to be demonstrated in coniferous trees.

Globally, organisms that have had foreign DNA introduced into their genome are considered to be GMOs and are subject to various levels of regulation. However, genome edited plants where the transgene has been removed by crossing and segregation, are not regulated as GMOs in many countries, including Australia, Argentina, Canada, Japan, and the USA [36, 37]. Yet, the European Union and New Zealand still considers such mutated plants to be GMOs and regulates them accordingly [38].

In conifers, removing transgenes by segregation is challenging due to their long breeding timescales. Genome editing mediated by direct delivery of CRISPR/Cas9 ribonucleoproteins (RNPs), circumvents the introduction of new DNA into the plant genome, and as above would not be regulated as GMOs in many countries [39]. The ability to produce edited plants without the requirement to undergo time consuming breeding to remove transgenes makes the use of RNP-mediated editing particularly attractive for slow-breeding conifers.

Pinus radiata D. Don., a conifer species native to California, is the world's most extensively planted exotic softwood [40] due to its high productivity and suitability for the construction timber, furniture, pulp and paper industries [41]. It is predominantly planted in Australia, Chile, and Spain and is the dominant species in New Zealand planted forests, where it comprises $90 \%$ of the planted production forest area and contributes $1.6 \%$ to GDP [42]. We have investigated the use of CRISPR/Cas9 to edit the $P$. radiata glucuronic acid substitution of the xylan 1 (GUX1) gene $[43,44]$ and demonstrated genome editing using DNA and RNPs.

\section{Results \\ Genome editing with single guide RNA (gRNA)}

We used the cell wall gene GUX1 (NCBI Accession No: MT628352) to investigate genome editing. Bioinformatic analysis (unpublished) has shown that only a single gene encoding the GUX1 protein is present in our in-house $P$. radiata and the publicly available Pinus taeda [45] genome sequences. Using a single gRNA at site1 (Fig. 1A), we generated 100 independent transgenic lines by cotransformation with two separate plasmids, one encoding CRISPR/Cas9 and the other, a gRNA and a selectable marker (Fig. S1A, B; Additional file 1). The control lines were transformed with the plasmid containing the gRNA and selectable marker but without the plasmid encoding CRISPR/Cas9. Transgenic embryogenic tissue growing on selective media was screened by Sanger sequencing of PCR products generated using primer1 and primer3 flanking the targeted region (Fig. 1A) to identify edited material. Initial testing identified 15 lines harbouring edits out of the 100 transgenic lines generated. All of the edited lines had a single base pair insertion or deletion at the target cut site (Fig. 1B, Fig. S2A; Additional file 2). Embryogenic tissue containing edits was matured to produce somatic embryos that were germinated to generate in vitro plantlets. Of the 15 edited lines, only 2 produced somatic embryos that were able to germinate. A total of 6 plantlets were produced, 5 plantlets germinating from line 1 and one from line 24 . DNA was extracted from needle material collected from these plantlets. The PCR products spanning the region of interest were sequenced to confirm edits. All the plantlets, as expected, contained a single base insertion or deletion (Fig. 1C, Fig. S2B; Additional file 2). No edits were found in the lines transformed with gRNA only 


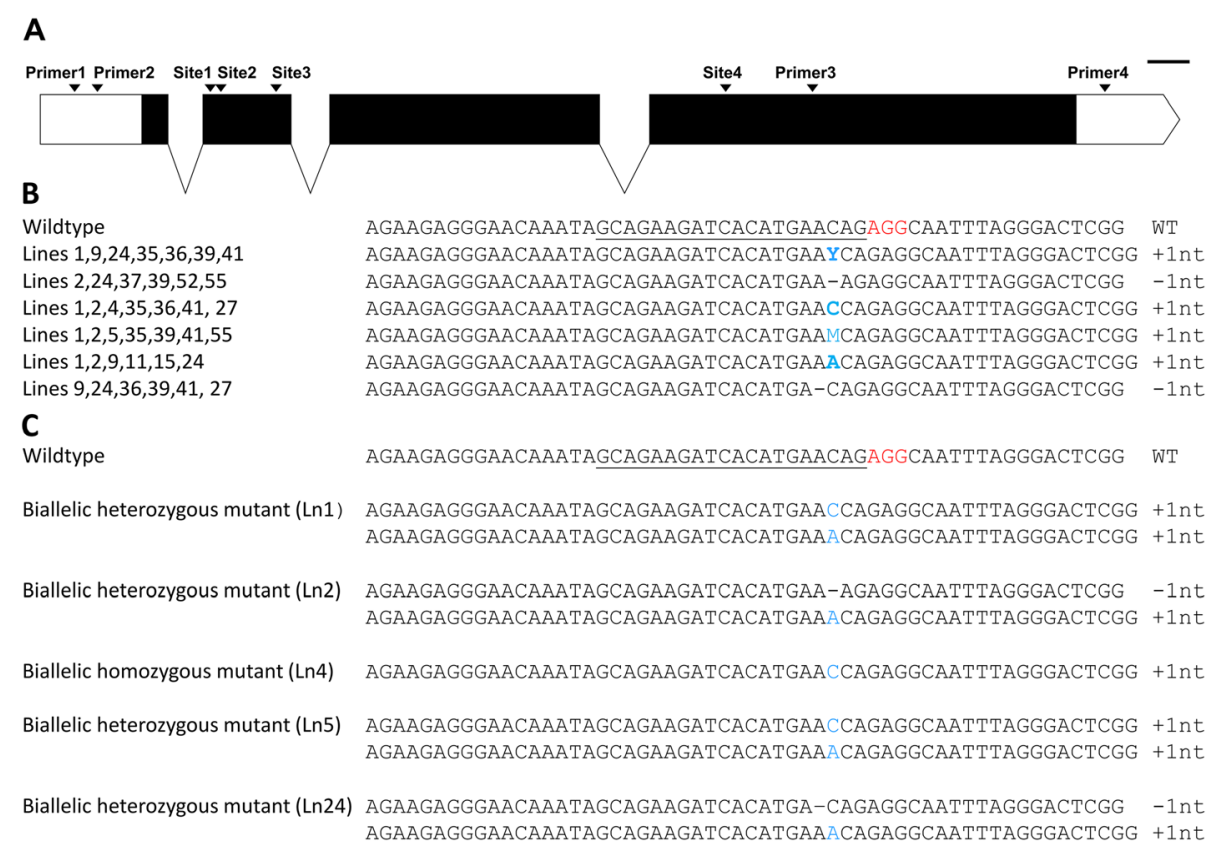

Fig. 1 Editing of GUX1with a single guide RNA. A. Graphical representation of the GUX1 gene sequence showing the gRNA target sites and primer binding sites. B. Pattern of edits identified in the 15 somatic embryogenic tissue lines. C. Allelic variations identified in different plantlets. Edited plantlet line numbers are denoted in parenthesis. CRISPR gRNA sites are underlined. Red text denotes the PAM site, blue text denotes insertions and "-" denotes deletions. ' $Y$ ' denotes a cytosine or thymine nucleotide. Scale bar $100 \mathrm{bp}$

constructs (Fig. S1A; Additional file 1). To further characterize the gene editing mediated modifications, we cloned the PCR products from the needles of the plantlets into an $E$. coli vector and sequenced 10 colonies derived from each plantlet. All insertions were either an adenine or cytosine base (Fig. 1C). No guanine or thymine insertion was detected in the edited plantlets. All the sequenced plantlets contained biallelic mutations, with one line being homozygous for the insertion (Fig. 1C). Different types of edits in the four edited plants (line 1 to line 5, Fig. 1C) originating from the same embryogenic tissue line was not expected. Line 3 died before analysis could be performed. Based on the in silico translated peptide sequence, the single base pair insertion/deletion is predicted to produce a nonfunctional truncated protein due to premature termination by an in-frame stop codon.

\section{Genome editing with two gRNAs}

A strategy using two gRNAs targeting sites $1.2 \mathrm{~kb}$ apart within the GUX1 gene (Fig. 2A) was tested for its ability to produce deletions that could be easily screened by PCR. One hundred transgenic lines were generated. Sequencing and subsequent analysis indicated that 12 lines $(12 \%)$ were successfully edited. The control lines were transformed with a plasmid encoding Cas9 and a selectable marker but not the gRNA encoding plasmid (Fig. S2; Additional file 2). Two embryogenic lines with deletions greater than $1 \mathrm{~kb}$ were identified (Fig. S3A; Additional file 3). Line 3 had a $1.2 \mathrm{~kb}$ deletion at the target cut sites (Fig. 2A, Fig. S2D; Additional file 2), while line 2 had a $1.37 \mathrm{~kb}$ deletion, 209 nucleotides downstream of target site 2 (Fig. 2A, Fig. S2C; Additional file 2). Other edited lines had single nucleotide insertions at one of the target sites (Fig. 2A). No edits were found in the 2

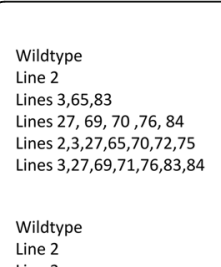

Fig. 2 Editing of GUX1 with two guide RNAs. A. Pattern of edits identified in the 12 somatic embryogenic tissue lines. B. Details of edits identified in needle tissue from germinated plantlets. CRISPR gRNA sites are underlined. Red font denotes the PAM site and blue font denotes insertions and "-" denotes deletions. 'R' denotes an adenine or guanine nucleotide, 'M' denotes an adenine or cytosine nucleotide 
lines transformed with Cas9 only construct. When the edited embryogenic tissue was matured to produce embryos, line 2 produced a single plantlet while 4 plantlets were produced from line 3 (Fig. 2B). PCR products, amplified from DNA extracted from needles, were cloned and sequenced from these plantlets. The plantlets did not harbour the $1.37 \mathrm{~kb}$ or the $1.2 \mathrm{~kb}$ deletions identified in the embryogenic tissue, instead the plantlets had a single insertion at target site 4 and were biallelic (Fig. 2B). Other successfully edited embryogenic lines did not produce plantlets. Like the earlier edits, these plantlets are predicted to introduce a premature stop codon producing a truncated protein.

\section{Genome editing with ribonucleoprotein (RNP) complexes}

To investigate the use of DNA-free genome editing in $P$. radiata, we tested the ability of directly delivered RNPs, comprising a Cas9 protein in complex with targeting gRNAs, to carry out editing. Because of challenges associated with direct selection of edited plantlets we used a hybrid approach to biolistically co-deliver RNPs with a plasmid-borne selectable marker (Fig. S1E) to select for antibiotic-resistant transformed/edited cells [46]. Two different commercial SpCas9 proteins; Alt-R SpCas9 3NLS and Alt-R SpCas9 V3 were tested for their ability to edit the GUX1 gene. Guide RNAs 142 bp apart (Fig. 3) were used with the intention of generating deletions. Twenty-two antibiotic-resistant transgenic embryogenic lines were generated for Alt-R SpCas9 3NLS and 12 lines for Alt-R SpCas9 V3. Alt-R SpCas9 3NLS produced 5 edited embryogenic lines (22\%) and Alt-R SpCas9 V3 produced 4 edited embryogenic lines (33\%). Embryogenic tissue showed a variety of editing patterns (Fig. 3). Six lines had a single nucleotide insertion at either one of the target sites. The single nucleotides inserted were either adenine, cytosine or thymine. Guanine insertions were not found in our analysis. Alt-R SpCas9 3NLS line 10 had a 142-nucleotide deletion between the target sites. Alt-R SpCas9 3NLS line 20 had a 1130 bp insertion at target site 1 (Fig. 3, Fig. S2E, Fig. S3B; Additional file 2 \& 3) while Alt-R SpCas9 V3 line 3 had a 10 bp deletion at target site 3 (Fig. 3, Fig. S2E). The edited embryogenic lines were then matured to produce embryos and subsequently plantlets. Germinated plantlets were then analysed by PCR amplification (Fig. S3B; Additional file 3), cloning and Sanger sequencing. All the resulting plantlets maintained the INDELs seen in their respective embryogenic tissue, including the142-nucleotide deletion in Alt-R SpCas9 3NLS line 10 (Fig. S2E, Fig. S3B; Additional file 2 \& 3). Alt-R SpCas9 3NLS line 20 did not produce plantlets (Fig. 3). All embryos/plantlets produced using RNPs were monoallelic.

\section{Discussion}

The CRISPR/Cas9 system is a powerful tool for targeted mutagenesis. It has been widely applied in model species and increasingly in plants of agronomic or horticultural importance $[47,48]$ and trees [35, 49, 50]. Here, we demonstrate CRISPR/Cas9- mediated genome editing in the commercially important coniferous tree $P$. radiata using both transgenic-mediated production of the editing complex and through the direct delivery of RNPs.

CRISPR/Cas is much simpler to implement than the other reported systems such as ZFN and TALEN [51, 52]. High-efficiency editing can be achieved even in large and complex plant genomes at each of the multiple targeted genomic loci $[53,54]$. In this study we demonstrate that this system can efficiently, and sitespecifically, edit an endogenous gene in $P$. radiata to produce mono- and bi-allelic mutations.

When editing with a single gRNA using a transgenic approach all edited plantlets had both alleles edited. Production of trees carrying a biallelic edit through crossing or selfing of monoallelic ones would be time consuming. Biallelic edits are desirable for rapid implementation. Targeting the GUX1 gene with a single gRNA produced single nucleotide INDELS. We did not see large deletions using a single gRNA as are frequently seen in other plant species [55-57]. In single gRNA edited plantlets all the insertions were either a cytosine or an adenine. The pattern of insertion or deletion is determined by nucleotide -4 from the protospacer associated motif (PAM) site [58]. The -4 nucleotide in the gRNA site1 (Fig. 1A) is an 'A', which is predicted to mainly show doublestrand break repair via insertion. A repeat of the PAMdistal nucleotide adjacent to the cut site is favoured over

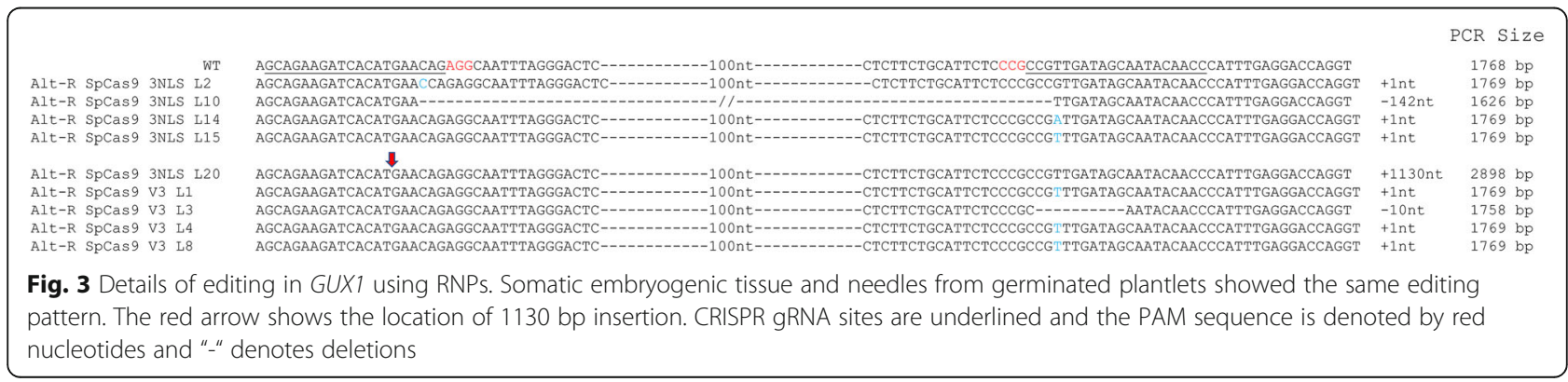


other nucleotides resulting, in this case, to be adenine [59]. When editing with a single guide RNA all plants were biallelic (carried edits in both alleles). However, only $20 \%$ of the edited plants that were regenerated carried the same edit on both alleles. Such biallelic edits are desirable for implementation as producing biallelic edits through crossing and segregation of trees carrying monoallelic ones would be time-consuming.

Screening of embryogenic tissue edited with two gRNAs identified large deletions in embryogenic tissue. However, none of the plantlets generated from this material contained these large deletions, instead the plantlets that were produced had only a single nucleotide insertion at one of the two target sites. This may be the result of the embryogenic tissue being chimeric because of delayed Cas9 cleavage occurring in the proliferating embryogenic tissue. This could result in plantlets being generated from differently edited sectors [60, 61]. Similar results have been observed in rice, where genomic deletions were present in transformed callus lines and plants with genomic deletions were rarely found [62]. Furthermore, the rate of genomic deletions with multiple gRNAs is considerably lower than single-site mutagenesis [63], which could have reduced the frequency of plants with large deletions.

It has been suggested that delayed Cas9 cleavage, after the first cell division, in proliferating cells can result in the production of chimeric editing $[60,61]$. This may be occurring in the proliferating embryogenic material with plants being generated from embryogenic material derived from different edited cells within the cell line to those identified in the initial screening. This may also explain why embryos carrying different edits were generated from the same embryogenic mass in experiments using a single gRNA.

Genome editing with RNPs has been successfully applied in several species using protoplasts [39, 64-66] and immature embryos $[67,68]$. In our study we have successfully edited $P$. radiata somatic embryogenic cells and produced plantlets using RNPs. All RNP edited plantlets were monoallelic, whereas plasmid-mediated CRISPR/Cas9 genome-edited plants were all biallelic. RNPs have a limited time frame for the cas9 protein to cleave DNA to mediate editing before they are degraded by endogenous proteases, resulting in a higher likelihood of monoallelic mutation [69]. All culture and transformation experiments were carried out at $23{ }^{\circ} \mathrm{C}$ which is below the optimum for the Cas 9 protein activity $\left(37^{\circ} \mathrm{C}\right)$ [70]. This sub-optimum temperature, combined with the short half-life of the RNP complex, may have contributed to the lack of biallelic edits. In contrast to editing using the transgenic delivery of the editing complex, deletions identified in embryogenic tissue were also present in the needles of plantlets produced from this tissue.
This is likely also a product of the limited window of activity for editing by RNPs. Edited tissue is likely to be homogenous, as editing would only occur in the cells prior to their first division.

Genome editing efficiency from methods using plasmid DNA and RNPs cannot be compared directly due to the different types of molecules and concentrations used for editing. The efficiency of genome editing using transgenic (12-15\%) and RNP (22-33\%) based delivery of the editing machinery are similar to those using comparable approaches in other plant species [48] and will support the development of efficient editing platforms.

To date gene editing has not been widely applied in tree species. Edited trees have been produced in several perennial fruit trees including, apple [64] and citrus [25, 71] and in the commercially important angiosperm hardwood tree species poplar and eucalyptus [32, 34, 72]. Proof-of-concept demonstrations of editing using protoplasts (without further growth of the edited material) are also available $[64,65]$ including recently for Larix gmelinii (Dahurian larch), a coniferous tree [73]. These examples, particularly demonstrations of editing in protoplasts, suggest that the key challenge to producing gene edited tree species is the lack of robust plant modification methodology. For instance, regeneration of trees from protoplasts of conifer species has resulted in limited success $[74,75]$ and regeneration of plants from transformed protoplasts of conifers has not been achieved yet. In our study edited plants have been produced from somatic embryogenic cell cultures.

\section{Conclusions}

In this work we have demonstrated genome editing in $P$. radiata using both transgenic and RNP approaches. As far as we are aware, this is the first published demonstration of genome edited trees being produced in a conifer species. This opens the way to apply genome editing for both fundamental science and economically and environmentally important trait improvements. Optimisation of RNP-based protocols, to achieve transgene free delivery, would facilitate rapid deployment where DNA-free editing is not regulated as a GMO.

\section{Methods}

\section{Vector construction and selection of target sequences}

Several different Pol III promoters have been used to produce guide RNAs for genome editing [48, 76, 77]. It has been suggested that endogenous promoters may result in higher gRNA expression than the widely used Arabidopsis or wheat promoters [78-80]. We assumed this may be beneficial and used the sequences of the A. thaliana U6-26 snRNA (NCBI accession no: X52528) [79] and wheat U6 gene (NCBI accession no: X63066) sequences [54] to identify upstream U6 promotor 
regions in the Pseudotsuga menziesii (Mirb.) Franco (Douglas fir) genome (V. 1.0) [81]. We verified the sequence of $\mathrm{U} 6$ promoter (NCBI accession no: MW757988) and used this sequence in all single gRNA constructs. For constructs expressing two guide RNAs we used the Douglas fir U6 promoter and the wheat U6 promoter listed above.

All editing targeted the GUX1 gene (NCBI accession no: MT628352) in P. radiata. Prior to gDNA design the genomic sequence of GUX1 was recovered from the genotype to be edited. Primers, Primer2 (5`CGATCT CTTGgCTTTtgagg $3^{\prime}$ ) and Primer4 (5`TGCCGT GTAGCTTATTGCAG 3' (Fig. 2A), were used to sequence both alleles. For editing, gDNAs site1: $5^{\prime}$ GCAGAAGATCACATGAACAGAGG 3`, site2: 5`ATTTAG GGACTCGGAAAGGGGG 3`, site3: 5` GGTTGTAT TGCTATCAACGGCGG 3` and site4: 5`AGCTGCAG GTTGGAAACTGCGG 3` were selected from regions without allelic differences (Fig. 2A). To increase the efficiency of genome editing gRNAs were designed according to the protocols of Dang et al. [82]. Additionally, the U6-26 terminator was added to the 3' end of the gRNA structure for double gRNA vectors. We used the online tools E-CRISP [83] and CRISPOR [84] to identify target sites in the gene (Fig. 2A). The target sites were selected based on efficiency and activity scores [85-87]. All vectors were synthesized by GenScript (Piscataway, NJ, USA). Vector maps are provided in Fig. S1 (Additional file 1).

\section{Plant transformation Plant material}

All experiments were carried out using previously cryopreserved somatic embryogenic cell lines of $P$. radiata that were initiated at Scion. These lines were established from immature embryos harvested from green cones and proliferated on Glitz2, a modified Litvay media [88] before being cryopreserved.

\section{Tissue preparation}

$P$. radiata somatic embryogenic cell lines, recovered from cryopreservation were proliferated by fortnightly lump transfers on a Litvay-based media [89] as modified by Hargreaves et al. (Glitz2) [88] with an additional $2 \mathrm{mg} / \mathrm{L}$ glycine. Three weeks prior to bombardment, tissue was suspended in GLITZ0 (Glitz2 liquid media with no plant growth regulators) (1 g fresh weight: $5 \mathrm{ml}$ liquid media). One $\mathrm{ml}$ aliquots of the suspension were pipetted onto sterile Whatman \#1 filter paper disks and placed onto fresh media. One week prior to bombardment, filter papers containing tissue were transferred to fresh media. Approximately $20 \mathrm{~h}$ prior to bombardment, tissue on the filter paper was re-suspended following the protocol described for the first suspension. The tissue in closed petri dishes was left in the laminar flow overnight to allow excess water to evaporate and bombarded the following day.

\section{Particle Bombardment using plasmid DNA}

Plasmid DNA $(2-5 \mu \mathrm{g})$ was precipitated onto gold particles $(<10 \mu \mathrm{m}$, Sigma Aldrich) by mixing with $50 \mu \mathrm{l}$ of gold $(1 \mathrm{mg} / 10 \mu \mathrm{l}), 20 \mu \mathrm{l}$ of $0.1 \mathrm{M}$ spermidine and $50 \mu \mathrm{l}$ of $2.5 \mathrm{M} \mathrm{CaCl}_{2}$. After $20 \mathrm{~min}$ at room temperature, $90 \mu \mathrm{l}$ of supernatant was removed and discarded. From the remaining solution, $5 \mu \mathrm{l}$ aliquots were placed onto six Swinnex filter holders (13 mm, Millipore, USA) for bombardment of the prepared somatic embryogenic tissue with a Particle Inflow Gun [90] using the following settings: helium pressure, $900 \mathrm{kpa}$; solenoid valve opening time, $30 \mathrm{~ms}$; shooting distance, $19 \mathrm{~cm}$ (lowest shelf position); chamber vacuum, $-96 \mathrm{kPa}(-14 \mathrm{psi})$. Tissue was then placed in a dark culture room at $24{ }^{\circ} \mathrm{C}$.

\section{CRISPR-RNP complex assembly (SpCas9/gRNA 1:1.2 molar ratio)}

Custom synthesized crRNAs (10 nmol), tracrRNA (100 nmol), Alt-R SpCas9 Nuclease 3NLS $(61 \mu \mathrm{M})$ and Alt-R SpCas9 nuclease V3 $(61.6 \mu \mathrm{M})$ were obtained from Integrated DNA Technologies, (Coralville, IA, USA). The lyophilized crRNAs and tracrRNA stocks were dissolved in nuclease free duplex buffer to obtain a concentration of $100 \mu \mathrm{M}$. To form $25 \mu \mathrm{M}$ gRNA duplexes (site1 or site 3); $3 \mu \mathrm{l}$ of crRNA and $3 \mu \mathrm{l}$ of tracrRNA were mixed with $6 \mu \mathrm{l}$ of duplex buffer and annealed by heating to $95^{\circ} \mathrm{C}$ for $5 \mathrm{~min}$ and slowly cooling to RT. The RNP complexes were assembled by mixing $6 \mu \mathrm{l}$ of each gRNA duplex with $2 \mu \mathrm{l}$ of Alt-R SpCas9 nuclease 3NLS or Alt$\mathrm{R}$ SpCas9 nuclease V3 and $1 \mu \mathrm{l}$ each of 10x PBS $(\mathrm{pH}$ 7.4) and sterile $\mathrm{H}_{2} \mathrm{O}$. The solution was carefully mixed by pipetting, incubated at RT for $30 \mathrm{~min}$ and stored at $-20^{\circ} \mathrm{C}$ until required.

\section{Particle Bombardment using Hybrid RNP complex/selection vector}

To prepare the gold particles $5 \mu \mathrm{l}$ of each RNP complex (site1 or site3) and $2.5 \mu \mathrm{l}$ of pRN2; a ZmUbi promoter:: NptII geneticin selection vector $(1.5 \mu \mathrm{g} / \mu \mathrm{l})$ [9] were added to a microfuge tube containing $7 \mathrm{mg}$ gold in $30 \mu \mathrm{l}$ sterile $\mathrm{H}_{2} \mathrm{O}$ and mixed thoroughly by pipetting. Particle bombardment was performed as above using $7 \mu \mathrm{l}$ aliquots of coated gold.

\section{Post bombardment selection}

After $24 \mathrm{~h}$, the filter papers with embryogenic tissue were placed onto selection media (Glitz2 containing $15 \mathrm{mg} / \mathrm{L}$ geneticin) and returned to the dark room. Four to eight weeks later putative transgenic tissue was isolated and proliferated on selection media for one month. 
Confirmed genome-edited embryogenic tissue was proliferated without selection until a sufficient amount of material was available for plant maturation protocols.

\section{Somatic embryo maturation and germination}

To obtain mature somatic embryos $5 \times 100 \mathrm{mg}$ lumps of 10-day old Glitz2-proliferated tissue were transferred onto a Litvay-based maturation medium containing $1 / 2$ strength Litvay macro nutrients, full strength micro nutrients (with the exception of manganese sulphate at $0.124 \mathrm{mM}$ concentration) [89], supplemented with the iron, vitamins, and amino acids from Smith EDM medium [91], $60 \mathrm{~g} / \mathrm{L}$ of sucrose, $56.7 \mu \mathrm{M}$ abscisic acid, and $8 \mathrm{~g} / \mathrm{L}$ gellan gum (Phytagel ${ }^{\circ}$, Sigma). Cultures were grown in the dark at $24^{\circ} \mathrm{C}$. After two weeks the tissue was subcultured onto fresh maturation media of the same composition and grown for a further 8-12 weeks. Mature somatic embryos were periodically harvested onto a modified BMG-2 [92, 93] germination medium, KNV87 [88], grown at $24{ }^{\circ} \mathrm{C}$ for 7 days in the dark, then an additional 7 days in low light (under shade-cloth) before being moved to full light conditions $(90 \mu \mathrm{mol}$ $\mathrm{m}^{-2} \mathrm{~s}^{-1}, 16 \mathrm{~h}$ photoperiod). Germinated embryos were moved to a modified Quoirin and Lepoivre medium (LP) [94, 95] containing $5 \mathrm{~g}$ activated charcoal (LPch) for plantlet multiplication or elongation, as described by $\mathrm{C}$ Hargreaves and M Menzies [96].

\section{Screening and analysis}

For initial screening, DNA was extracted using CTAB [97] from 30 to $50 \mathrm{mg}$ of post bombardment embryogenic tissue growing on selective media and screened for editing by PCR and sequencing. PCR was performed using $50 \mathrm{ng}$ of genomic DNA and Q5 polymerase (NEB) following the manufacturer's instructions with annealing conditions of $60^{\circ} \mathrm{C}$ for $30 \mathrm{~s}$ and using primer1 $\left(5^{\circ}\right.$ CCTGAAAACCCTAACCTGCTTC $\left.3^{\prime}\right)$ and primer3 $\left(5^{\prime}\right.$ CCAGAGTTGAAGAGTGTTGCAT 3’) (Fig. 2A). PCR products were either gel extracted or purified using exonuclease I and shrimp alkaline phosphatase (Exo-SAP) and sequenced by Sanger sequencing using primer 2 and primer3 (Fig. 2A). Sequencing results were analysed by manual screening and the online tools ICE (https://ice. synthego.com/) and TIDE (http://shinyapps. datacurators.nl/tide/) [98]. Embryogenic tissue confirmed to harbour GUX1 edits were matured to produce somatic embryos and these were germinated and multiplied. Putatively edited plantlets were then characterized by cloning of PCR products generated from the plantlets into an $E$. coli vector and sequencing of 10 independent clones for each plantlet.

\section{Abbreviations}

CRISPR: Clustered regularly interspaced short palindromic repeats;

ICE: Inference of CRISPR Edits; INDEL: Insertion or deletion; PCR: Polymerase chain reaction; snRNA: Small nuclear RNA; TALEN: Transcription activator-like effector nucleases; TIDE: Tracking of Indels by Decomposition; ZFN: Zinc finger nuclease

\section{Supplementary Information}

The online version contains supplementary material available at https://doi. org/10.1186/s12870-021-03143-x

Additional file 1: Figure S1. Vector maps of plasmids used in transformation experiments.

Additional file 2: Figure S2. Chromatograms of sequencing done on the edited embryogenic tissue and plants.

Additional file 3: Figure S3. Electrophoresis gel pictures of PCR from editing with plasmid DNA and RNPS.

Additional file 4: Table S1. Summary of somatic embryogenic lines and plants generated.

\section{Acknowledgements}

The authors thank the internal reviewers for critical reading of this manuscript. We also thank the tissue culture personnel for their assistance in maintaining and cryopreservation of the embryogenic cell lines.

\section{Authors' contributions}

CP performed transgenic genome editing with single and double gRNAs. LP performed genome editing with RNP. BG conducted all transformations and plant culture. CR provided all tissue culture material and conducted maturation media development. MS and GT conceived and directed the work. All authors read and approved the manuscript.

\section{Funding}

This study was financially supported by the New Zealand Ministry of Business, Innovation and Employment contract (MBIE) no: C04×1707 to MS. RNP work was supported by the 'Turbo-breeding for New Zealand's plant industries' collaboration with Plant \& Food Research Limited (MBIE contract: C11 $\times 1602)$ and Scion's Platforms Plan (MBIE contract: C04×1703). The funding agencies had no role in the study design, performance, data collection and analysis, decision to publish, or preparation/writing of the manuscript.

\section{Availability of data and materials}

The sequence of PrGUX1 has been deposited in GenBank of NCBI with accession No. of MT628352.1 (https://www.ncbi.nlm.nih.gov/nuccore/MT62 8352.1/). The sequence of Pseudotsuga menziesii (Douglas fir) U6 small nuclear snRNA (U6) gene sequence has been deposited in GenBank of NCBI with accession No. of MW757988.1 (https://www.ncbi.nlm.nih.gov/nuccore/ MW757988). All other data generated or analysed during this study are included in this published article.

\section{Declarations}

Ethics approval and consent to participate Not applicable.

Consent for publication

Not applicable.

\section{Competing interests}

The authors declare that they have no competing interests.

Received: 18 November 2020 Accepted: 7 July 2021

Published online: 10 August 2021

\section{References}

1. WWF living forests report. Chap. 5: Saving forests at risk http://awsassets.pa nda.org/downloads/living_forests_report_chapter_5_1.pdf.

2. Payn T, Carnus J-M, Freer-Smith P, Kimberley M, Kollert W, Liu S, Orazio C, Rodriguez L, Silva LN, Wingfield MJ. Changes in planted forests and future global implications. For Ecol Manage. 2015;352:57-67. 
3. Burdon R, Carson M, Shelbourne C. Achievements in forest tree genetic improvement in Australia and New Zealand 10: Pinus radiata in New Zealand. Australian Forestry. 2008;71(4):263-79.

4. Isaac-Renton M, Stoehr M, Statland CB, Woods J. Tree breeding and silviculture: Douglas-fir volume gains with minimal wood quality loss under variable planting densities. For Ecol Manage. 2020:465:118094.

5. Lenz PRN, Beaulieu J, Mansfield SD, Clement S, Desponts M, Bousquet J. Factors affecting the accuracy of genomic selection for growth and wood quality traits in an advanced-breeding population of black spruce (Picea mariana). BMC Genom. 2017;18(1):335.

6. Grattapaglia D, Silva-Junior OB, Resende RT, Cappa EP, Muller BSF, Tan B, Isik F, Ratcliffe B, El-Kassaby YA. Quantitative genetics and genomics converge to accelerate forest tree breeding. Front Plant Sci. 2018;9(1693):1693.

7. Li Y, Dungey HS. Expected benefit of genomic selection over forward selection in conifer breeding and deployment. PLoS One. 2018;13(12): e0208232.

8. Henderson AR, Walter C. Genetic engineering in conifer plantation forestry. Silvae Genet. 2006;55(1-6):253-62.

9. Grace LJ, Charity JA, Gresham B, Kay N, Walter C. Insect-resistant transgenic Pinus radiata. Plant Cell Rep. 2005;24(2):103-11.

10. Lachance D, Hamel L-P, Pelletier F, Valéro J, Bernier-Cardou M, Chapman K, Van Frankenhuyzen K, Séguin A. Expression of a Bacillus thuringiensis crylAb gene in transgenic white spruce and its efficacy against the spruce budworm (Choristoneura fumiferana). Tree Genet Genomes. 2007;3(2):153-67.

11. Bishop-Hurley SL, Zabkiewicz RJ, Grace L, Gardner RC, Wagner A, Walter C. Conifer genetic engineering: transgenic Pinus radiata (D. Don) and Picea abies (Karst) plants are resistant to the herbicide Buster. Plant Cell Rep. 2001; 20(3):235-43.

12. Charity JA, Holland L, Grace LJ, Walter C. Consistent and stable expression of the $n p t l l$, uidA and bar genes in transgenic Pinus radiata after Agrobacterium tumefaciens-mediated transformation using nurse cultures. Plant Cell Rep. 2005;23(9):606-16.

13. Wadenbäck J, von Arnold S, Egertsdotter U, Walter MH, Grima-Pettenati J, Goffner D, Gellerstedt G, Gullion T, Clapham D. Lignin biosynthesis in transgenic Norway spruce plants harboring an antisense construct for cinnamoyl CoA reductase (CCR). Transgenic res. 2008;17(3):379-92.

14. Wagner A, Tobimatsu Y, Phillips L, Flint H, Torr K, Donaldson L, Pears L, Ralph J. CCOAOMT suppression modifies lignin composition in Pinus radiata. Plant J. 2011;67(1):119-29.

15. Tang W, Peng X, Newton RJ. Enhanced tolerance to salt stress in transgenic loblolly pine simultaneously expressing two genes encoding mannitol-1phosphate dehydrogenase and glucitol-6-phosphate dehydrogenase. Plant Physiol Biochem. 2005;43(2):139-46.

16. Zhang C, Norris-Caneda KH, Rottmann WH, Gulledge JE, Chang S, Kwan BY, Thomas AM, Mandel LC, Kothera RT, Victor AD, et al. Control of pollenmediated gene flow in transgenic trees. Plant Physiol. 2012;159(4):1319-34.

17. Myburg AA, Hussey SG, Wang JP, Street NR, Mizrachi E. Systems and synthetic biology of forest trees: a bioengineering paradigm for woody biomass feedstocks. Front Plant Sci. 2019;10(775):775

18. Sarmast MK. Genetic transformation and somaclonal variation in conifers. Plant Biotechnology Reports. 2016;10(6):309-25.

19. Nehra NS, Becwar MR, Rottmann WH, Pearson L, Chowdhury K, Chang S, Dayton Wilde H, Kodrzycki RJ, Zhang C, Gause KC, et al. Forest biotechnology: Innovative methods, emerging opportunities. In Vitro Cell Dev Biol Plant. 2005;41(6):701-17.

20. Urnov FD, Rebar EJ, Holmes MC, Zhang HS, Gregory PD. Genome editing with engineered zinc finger nucleases. Nat Rev Genet. 2010;11(9):636-46.

21. Fritsche S, Klocko AL, Boron A, Brunner AM, Thorlby G. Strategies for engineering reproductive sterility in plantation forests. Front Plant Sci. 2018:9:1671.

22. Arora L, Narula A. Gene Editing and Crop Improvement Using CRISPR-Cas9 System. Front Plant Sci. 2017;8:1932

23. Calyxt. First commercial sale of Calyxt high oleic soybean oil on the U.S. market. St. Paul: Calyx; 2019.

24. Joshi RK, Bharat SS, Mishra R. Engineering drought tolerance in plants through CRISPR/Cas genome editing. 3 Biotech. 2020;10(9):400.

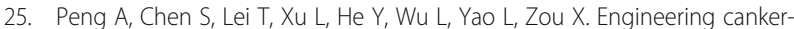
resistant plants through CRISPR/Cas9-targeted editing of the susceptibility gene CSLOB1 promoter in citrus. Plant Biotechnol J. 2017:15(12):1509-19.

26. Wang F, Wang C, Liu P, Lei C, Hao W, Gao Y, Liu YG, Zhao K. Enhanced Rice Blast Resistance by CRISPR/Cas9-Targeted Mutagenesis of the ERF Transcription Factor Gene OsERF922. PLoS One. 2016;11(4):e0154027.
27. Zhou H, He M, Li J, Chen L, Huang Z, Zheng S, Zhu L, Ni E, Jiang D, Zhao B, et al. Development of Commercial Thermo-sensitive Genic Male Sterile Rice Accelerates Hybrid Rice Breeding Using the CRISPR/Cas9-mediated TMS5 Editing System. Sci Rep. 2016;6:37395.

28. Sun Y, Zhang X, Wu C, He Y, Ma Y, Hou H, Guo X, Du W, Zhao Y, Xia L. Engineering Herbicide-Resistant Rice Plants through CRISPR/Cas9-Mediated Homologous Recombination of Acetolactate Synthase. Mol Plant. 2016;9(4):628-31.

29. Tian S, Jiang L, Cui X, Zhang J, Guo S, Li M, Zhang H, Ren Y, Gong G, Zong $M$, et al. Engineering herbicide-resistant watermelon variety through CRISPR/Cas9-mediated base-editing. Plant Cell Rep. 2018;37(9):1353-6.

30. Soyk S, Lemmon ZH, Oved M, Fisher J, Liberatore KL, Park SJ, Goren A, Jiang K, Ramos A, van der Knaap E, et al. Bypassing negative epistasis on yield in tomato imposed by a domestication gene. Cell. 2017;169(6):1142-55.e1112.

31. Zhang H, Si X, Ji X, Fan R, Liu J, Chen K, Wang D, Gao C. Genome editing of upstream open reading frames enables translational control in plants. Nat Biotechnol. 2018;36(9):894-8.

32. Bruegmann T, Deecke $K$, Fladung M. Evaluating the Efficiency of gRNAs in CRISPR/Cas9 Mediated Genome Editing in Poplars. Int J Mol Sci. 2019;20(15):3623.

33. Muller NA, Kersten B, Leite Montalvao AP, Mahler N, Bernhardsson C, Brautigam K, Carracedo Lorenzo Z, Hoenicka H, Kumar V, Mader M, et al. A single gene underlies the dynamic evolution of poplar sex determination. Nat Plants. 2020;6(6):630-7.

34. Dai Y, Hu G, Dupas A, Medina L, Blandels N, Clemente HS, Ladouce N, Badawi M, Hernandez-Raquet G, Mounet F, et al. Implementing the CRISPR/ Cas9 technology in eucalyptus hairy roots using wood-related genes. Int J Mol Sci. 2020;21(10):3408.

35. Fan D, Liu T, Li C, Jiao B, Li S, Hou Y, Luo K. Efficient CRISPR/Cas9-mediated targeted mutagenesis in populus in the first generation. Sci Rep. 2015;5:12217.

36. Whelan Al, Lema MA. Regulatory framework for gene editing and other new breeding techniques (NBTs) in Argentina. GM Crops Food. 2015;6(4):253-65.

37. Ishii T, Araki M. A future scenario of the global regulatory landscape regarding genome-edited crops. GM Crops Food. 2017:8(1):44-56

38. Fritsche S, Poovaiah C, MacRae E, Thorlby G. A New Zealand perspective on the application and regulation of gene editing. Front Plant Sci. 2018;9:1323.

39. Woo JW, Kim J, Kwon SI, Corvalan C, Cho SW, Kim H, Kim SG, Kim ST, Choe S, Kim JS. DNA-free genome editing in plants with preassembled CRISPRCas9 ribonucleoproteins. Nat Biotechnol. 2015;33(11):1162-4.

40. Mead DJ. Sustainable management of Pinus radiata plantations. Food and agriculture organization of the United nations (FAO); 2013.

41. Kininmonth J, Whitehouse L: Properties and uses of radiata pine. Rotorua: New Zealand Ministry of Forestry, Forest Research Institute; 1992.

42. National exotic forest description. https://www.mpi.govt.nz/ dmsdocument/34425-2019-nefd-report-pdf.

43. Mortimer JC, Miles GP, Brown DM, Zhang Z, Segura MP, Weimar T, Yu X, Seffen KA, Stephens E, Turner SR, et al. Absence of branches from xylan in Arabidopsis gux mutants reveals potential for simplification of lignocellulosic biomass. Proc Natl Acad Sci U S A. 2010;107(40):17409-14.

44. Rennie EA, Hansen SF, Baidoo EE, Hadi MZ, Keasling JD, Scheller HV. Three members of the Arabidopsis glycosyltransferase family 8 are xylan glucuronosyltransferases. Plant Physiol. 2012;159(4):1408-17.

45. Kovach A, Wegrzyn JL, Parra G, Holt C, Bruening GE, Loopstra CA, Hartigan J, Yandell M, Langley $\mathrm{CH}$, Korf I. The Pinus taeda genome is characterized by diverse and highly diverged repetitive sequences. BMC Genomics. 2010;11(1):1-14.

46. Banakar R, Eggenberger AL, Lee K, Wright DA, Murugan K, Zarecor S, Lawrence-Dill CJ, Sashital DG, Wang K. High-frequency random DNA insertions upon co-delivery of CRISPR-Cas9 ribonucleoprotein and selectable marker plasmid in rice. Sci Rep. 2019;9(1):19902.

47. Jiang W, Zhou H, Bi H, Fromm M, Yang B, Weeks DP. Demonstration of CRISPR/Cas9/sgRNA-mediated targeted gene modification in Arabidopsis, tobacco, sorghum and rice. Nucleic Acids Res. 2013;41(20):e188.

48. Shan Q, Wang Y, Li J, Zhang Y, Chen K, Liang Z, Zhang K, Liu J, Xi JJ, Qiu JL, et al. Targeted genome modification of crop plants using a CRISPR-Cas system. Nat Biotechnol. 2013;31(8):686-8.

49. Jia H, Wang N. Targeted genome editing of sweet orange using Cas9/ sgRNA. PLoS One. 2014;9(4):e93806.

50. Zhou X, Jacobs TB, Xue L, Harding SA, Tsai CJ. Exploiting SNPs for biallelic CRISPR mutations in the outcrossing woody perennial Populus reveals 4coumarate:CoA ligase specificity and redundancy. New Phytol. 2015;208(2): 298-301.

51. Liu H, Liu C, Zhao Y-h, Han X-j, Zhou Z-w, Wang C, Li R-f. Li X-l: Comparing successful gene knock-in efficiencies of CRISPR/Cas9 with ZFNs and TALENs 
gene editing systems in bovine and dairy goat fetal fibroblasts. Journal of Integrative Agriculture. 2018;17(2):406-14.

52. Zhang J, Liu J, Yang W, Cui M, Dai B, Dong Y, Yang J, Zhang X, Liu D, Liang H, et al. Comparison of gene editing efficiencies of CRISPR/Cas9 and TALEN for generation of MSTN knock-out cashmere goats. Theriogenology. 2019;132:1-11.

53. Wang Y, Cheng X, Shan Q, Zhang Y, Liu J, Gao C, Qiu JL. Simultaneous editing of three homoeoalleles in hexaploid bread wheat confers heritable resistance to powdery mildew. Nat Biotechnol. 2014;32(9):947-51.

54. Qi W, Zhu T, Tian Z, Li C, Zhang W, Song R. High-efficiency CRISPR/Cas9 multiplex gene editing using the glycine tRNA-processing system-based strategy in maize. BMC Biotechnol. 2016;16(1):58.

55. Banfalvi Z, Csakvari E, Villanyi V, Kondrak M. Generation of transgene-free PDS mutants in potato by Agrobacterium-mediated transformation. BMC Biotechnol. 2020;20(1):25.

56. Zhu S, Yu X, Li Y, Sun Y, Zhu Q, Sun J. Highly Efficient Targeted Gene Editing in Upland Cotton Using the CRISPR/Cas9 System. Int J Mol Sci. 2018; 19(10):3000.

57. Li M, Li X, Zhou Z, Wu P, Fang M, Pan X, Lin Q, Luo W, Wu G, Li H. Reassessment of the Four Yield-related Genes Gn1a, DEP1, GS3, and IPA1 in Rice Using a CRISPR/Cas9 System. Front Plant Sci. 2016;7:377.

58. Chakrabarti AM, Henser-Brownhill T, Monserrat J, Poetsch AR, Luscombe NM, Scaffidi P. Target-Specific Precision of CRISPR-Mediated Genome Editing. Mol Cell. 2019;73(4):699-713 e696.

59. Allen F, Crepaldi L, Alsinet C, Strong AJ, Kleshchevnikov V, De Angeli $P$, Palenikova P, Khodak A, Kiselev V, Kosicki M, et al. Predicting the mutations generated by repair of Cas9-induced double-strand breaks. Nat Biotechnol. 2018;37(1):64-72.

60. Mercx S, Tollet J, Magy B, Navarre C, Boutry M. Gene Inactivation by CRISPRCas9 in Nicotiana tabacum BY-2 Suspension Cells. Front Plant Sci. 2016; 7(40):40.

61. Klimek-Chodacka M, Oleszkiewicz T, Lowder LG, Qi Y, Baranski R. Efficient CRISPR/Cas9-based genome editing in carrot cells. Plant Cell Rep. 2018; 37(4):575-86.

62. Pathak B, Zhao S, Manoharan M, Srivastava V. Dual-targeting by CRISPR/Cas9 leads to efficient point mutagenesis but only rare targeted deletions in the rice genome. 3 Biotech. 2019;9(4):158.

63. Durr J, Papareddy R, Nakajima K, Gutierrez-Marcos J. Highly efficient heritable targeted deletions of gene clusters and non-coding regulatory regions in Arabidopsis using CRISPR/Cas9. Sci Rep. 2018;8(1):4443.

64. Malnoy M, Viola R, Jung MH, Koo OJ, Kim S, Kim JS, Velasco R, Nagamangala Kanchiswamy C. DNA-Free Genetically Edited Grapevine and Apple Protoplast Using CRISPR/Cas9 Ribonucleoproteins. Front Plant Sci. 2016;7:1904.

65. Fan Y, Xin S, Dai X, Yang X, Huang H, Hua Y. Efficient genome editing of rubber tree (Hevea brasiliensis) protoplasts using CRISPR/Cas9 ribonucleoproteins. Indust Crops Prod. 2020;146:112146.

66. Subburaj S, Chung SJ, Lee C, Ryu SM, Kim DH, Kim JS, Bae S, Lee GJ. Sitedirected mutagenesis in Petunia $\mathrm{x}$ hybrida protoplast system using direct delivery of purified recombinant Cas9 ribonucleoproteins. Plant Cell Rep. 2016;35(7):1535-44.

67. Liang Z, Chen K, Li T, Zhang Y, Wang Y, Zhao Q, Liu J, Zhang H, Liu C, Ran Y. Efficient DNA-free genome editing of bread wheat using CRISPR/Cas9 ribonucleoprotein complexes. Nat Commun. 2017:8(1):1-5.

68. Svitashev S, Schwartz C, Lenderts B, Young JK, Mark Cigan A. Genome editing in maize directed by CRISPR-Cas9 ribonucleoprotein complexes. Nat Commun. 2016;7(1):13274.

69. Kim S, Kim D, Cho SW, Kim J, Kim JS. Highly efficient RNA-guided genome editing in human cells via delivery of purified Cas9 ribonucleoproteins. Genome Res. 2014;24(6):1012-9.

70. Xiang G, Zhang X, An C, Cheng C, Wang H. Temperature effect on CRISPRCas9 mediated genome editing. J Genet Genomics. 2017;44(4):199-205.

71. Jia H, Xu J, Orbovic V, Zhang Y, Wang N. Editing Citrus Genome via SaCas9/ sgRNA System. Front Plant Sci. 2017;8:2135.

72. Elorriaga E, Klocko AL, Ma C, Strauss SH. Variation in Mutation Spectra Among CRISPR/Cas9 Mutagenized Poplars. Front Plant Sci. 2018;9:594.

73. Ren Q, Sretenovic S, Liu S, Tang X, Huang L, He Y, Liu L, Guo Y, Zhong Z, Liu G, et al. PAM-less plant genome editing using a CRISPR-SpRY toolbox. Nat Plants. 2021;7(1):25-33.

74. Attree SM, Dunstan DI, Fowke LC. Plantlet Regeneration from Embryogenic Protoplasts of White Spruce (Picea Glauca). Nat Biotechnol. 1989;7:1060-2.

75. Klimaszewska K. Recovery of somatic embryos and plantlets from protoplast cultures of Larix $\times$ eurolepis. Plant Cell Rep. 1989:8(8):440-4.
76. Cong L, Ran FA, Cox D, Lin S, Barretto R, Habib N, Hsu PD, Wu X, Jiang W, Marraffini LA, et al. Multiplex genome engineering using CRISPR/Cas systems. Science. 2013;339(6121):819-23.

77. Mali P, Yang L, Esvelt KM, Aach J, Guell M, DiCarlo JE, Norville JE, Church GM. RNA-Guided Human Genome Engineering via Cas9. Science. 2013; 339(6121):823-6.

78. Dai X, Yang X, Wang C, Fan Y, Xin S, Hua Y, Wang K, Huang H. CRISPR/Cas9mediated genome editing in Hevea brasiliensis. Industr Crops Prod. 2021;164: 113418.

79. Lei J, Li Y, Xu X, Aerzuguli T, Pu Y, Zhang J, Liu X. Cloning and functional analysis of different truncated GbU6 promoters in cotton. Acta Agronomica Sinica. 2016;42(5):675-83.

80. Long L, Guo D-D, Gao W, Yang W-W, Hou L-P, Ma X-N, Miao Y-C, Botella JR, Song C-P. Optimization of CRISPR/Cas9 genome editing in cotton by improved sgRNA expression. Plant Methods. 2018;14(1):1-9.

81. Good PD, Krikos AJ, Li SX, Bertrand E, Lee NS, Giver L, Ellington A, Zaia JA, Rossi JJ, Engelke DR. Expression of small, therapeutic RNAs in human cell nuclei. Gene Ther. 1997;4(1):45-54.

82. Dang Y, Jia G, Choi J, Ma H, Anaya E, Ye C, Shankar P, Wu H. Optimizing sgRNA structure to improve CRISPR-Cas9 knockout efficiency. Genome Biol. 2015;16:280.

83. Heigwer F, Kerr G, Boutros M. E-CRISP: fast CRISPR target site identification. Nat Methods. 2014;11(2):122-3.

84. Haeussler M, Schonig K, Eckert H, Eschstruth A, Mianne J, Renaud JB, Schneider-Maunoury S, Shkumatava A, Teboul L, Kent J, et al. Evaluation of off-target and on-target scoring algorithms and integration into the guide RNA selection tool CRISPOR. Genome Biol. 2016;17(1):148.

85. Doench JG, Fusi N, Sullender M, Hegde M, Vaimberg EW, Donovan KF, Smith I, Tothova Z, Wilen C, Orchard R, et al. Optimized sgRNA design to maximize activity and minimize off-target effects of CRISPR-Cas9. Nat Biotechnol. 2016;34(2):184-91.

86. Doench JG, Hartenian E, Graham DB, Tothova Z, Hegde M, Smith I, Sullender M, Ebert BL, Xavier RJ, Root DE. Rational design of highly active sgRNAs for CRISPR-Cas9-mediated gene inactivation. Nat Biotechnol. 2014;32(12):1262-7.

87. Xu H, Xiao T, Chen CH, Li W, Meyer CA, Wu Q, Wu D, Cong L, Zhang F, Liu JS, et al. Sequence determinants of improved CRISPR sgRNA design. Genome Res. 2015;25(8):1147-57.

88. Hargreaves C, Reeves C, Gough K, Montalbán IA, Low C, Van Ballekom S, Dungey HS, Moncaleán P. Nurse tissue for embryo rescue: testing new conifer somatic embryogenesis methods in a F1 hybrid pine. Trees. 2016;31(1):273-83.

89. Litvay JD, Verma DC, Johnson MA. Influence of a loblolly pine (Pinus taeda L.). Culture medium and its components on growth and somatic embryogenesis of the wild carrot (Daucus carota L.). Plant Cell Rep. 1985;4(6):325-8.

90. Davies KM, Deroles SC, Boase MR, Hunter DA, Schwinn KE: Biolistics-based gene silencing in plants using a modified particle inflow gun. In: Biolistic DNA Delivery. Totowa: Humana Press; 2013. p. 63-74.

91. Smith DR. Growth medium. US Patent No. 1996:5:565,355.

92. Krogstrup P. Embryo like structures from cotyledons and ripe embryos of Norway spruce (Picea abies). Can J For Res. 1986;16(3):664-8.

93. Krogstrup P, Eriksen EN, Møller JD, Roulund H. Somatic embryogenesis in sitka spruce (Picea sitchensis (Bong.) Carr.). Plant Cell Rep. 1988;7(7):594-7.

94. Quoirin $M$, Lepoivre P. Etude de milieux adaptes aux cultures in vitro de Prunus. Acta Hort. 1977;78:437-42.

95. Aitken-Christie J, Singh AP, Davies H. Multiplication of meristematic tissue: A new tissue culture system for radiata pine. In: Genetic manipulation of woody plants. Boston: Springer; 1988. pp. 413-32.

96. Hargreaves C, Menzies M: Organogenesis and cryopreservation of juvenile radiata pine. In: Protocols for micropropagation of woody trees and fruits. Dordrecht: Springer; 2007. p. 51-65.

97. Cato S, Richardson T. Inter-and intraspecific polymorphism at chloroplast SSR loci and the inheritance of plastids in Pinus radiata D. Don. Theor Appl Genet. 1996;93(4):587-92.

98. Brinkman EK, Chen T, Amendola M, van Steensel B. Easy quantitative assessment of genome editing by sequence trace decomposition. Nucleic Acids Res. 2014;42(22):e168.

\section{Publisher's Note}

Springer Nature remains neutral with regard to jurisdictional claims in published maps and institutional affiliations. 